\section{CALENDARIOS, RELOJES Y UN CAJERO AUTOMÁTICO. CINCO PATENTES EN LA REGIÓN DE MURCIA Y DOS APLICACIONES DE PUBLICIDAD (1887-1928)}

\author{
Pascual Santos López \\ Universidad de Murcia \\ IES Diego Tortosa (Cieza) \\ pascual.santos@murciaeduca.es
}

\section{CALENDARS, CLOCKS AND A CASH MACHINE. FIVE PATENTS IN THE REGIÓN DE MURCIA AND TWO ADVERTISING APPLICATIONS (1887-1928)}

Cómo citar este artículo/Citation: Santos López, P. (2014). "Calendarios, relojes y un cajero automático. Cinco patentes en la Región de Murcia y dos aplicaciones de publicidad (1887-1928)". Arbor, 190 (769): a165. doi: http://dx.doi. org/10.3989/arbor.2014.769n5004

Recibido: 22 noviembre 2013. Aceptado: 28 junio 2014.

RESUMEN: A finales del siglo XIX y principios del XX, relojes y calendarios eran objetos de uso cotidiano y se encontraban en hogares, aulas y lugares de trabajo. La publicidad en la prensa del cambio de siglo demuestra la demanda que tenían estos objetos relacionados con la medida del tiempo. Esta demanda espoleó el ingenio de nuestros inventores que se apresuraron a patentar máquinas que controlaban el tiempo, que utilizaban el tiempo como control o simplemente que explotaban la curiosidad y fascinación que provocaban estos aparatos. Entre 1887 y 1928 se patentan en la Región de Murcia cinco ingenios relacionados con la medida del tiempo. Dos calendarios en 1887, un cajero automático en 1913 y dos inventos en 1928 en los que se aprovechan la curiosidad y la necesidad de medir el tiempo para atraer la atención del público. Analizaremos estas cinco patentes y la prensa del momento para acercarnos a sus inventores, sus logros y la época en que vivieron.

PALABRAS CLAVE: Calendario; Reloj; Cajero automático; Patente; Publicidad; Cartagena; Cieza; Murcia; Siglos XIX y XX.
Copyright: (C) 2014 CSIC. Este es un artículo de acceso abierto distribuido bajo los términos de la licencia Creative Commons Attribution-Non Commercial (by-nc) Spain 3.0.

ABSTRACT: By the late nineteenth and early twentieth centuries, clocks and calendars had become everyday objects in homes, classrooms and workplaces. Advertising in the press at the turn of century shows there to have been demand for various sorts of timepiece. This demand spurred the intellectual efforts of inventors who rushed to patent devices either to measure or register the passing of time or simply to satisfy the curiosity these fascinating devices aroused. Five time-measurement-related inventions were patented in the Region of Murcia between 1887 and 1928. Two calendars in 1887, an automated cash machine in 1913 and two inventions in 1928 that exploited the curiosity and the need to measure the time to attract the public's attention. We discuss these five patents and the contemporary press to get closer to their inventors, achievements and the time in which they lived.

KEYWORDS: Calendar; Clock; Automated cash machine; Patent; Advertising; Cartagena; Cieza; Murcia; 19-20th Centuries. 


\section{INTRODUCCIÓN}

A lo largo de la historia de la humanidad infinidad de hitos han estado relacionados con el control del tiempo: cambios en el inicio de los días del mes, instauración y reforma de calendarios, invención y desarrollo de mecanismos de relojería y máquinas automáticas que podían realizar diferentes acciones al cumplir un tiempo determinado. Uno de esos hitos fue el invento de la clepsidra o reloj de agua, también llamado reloj de noche o de invierno, ya que hasta el momento solo se conocía el reloj de sol. Dicho reloj funcionaba dejando escapar el agua por un fino agujero. Además, podía incorporar un flotador asociado a un mecanismo piñón-cremallera para que marcara las horas o hiciera sonar algún tipo de alarma.

Ya en el siglo VIII se tienen noticias de relojes movidos por contrapesas, como el que "el papa Paulo I le regaló al rey Pipino el Breve" (Barquero, 2004, p. 40). Pero es hacia finales del siglo XIII cuando los relojes mecánicos se hicieron habituales en abadías y monasterios como respuesta a la necesidad monástica de conocer las horas de oración. Pasando, durante el siglo XIV, a incorporarse a las ciudades (Mayr, 2012, p. 17). Los relojes de torre en combinación con las campanas regulaban la vida de la ciudad y marcaban el comienzo y final de cualquier actividad pública. Las ciudades se organizaron mucho mejor gracias al invento del áncora Verge y Foliot, que retrasaba la aceleración de una pesa colgante haciendo que se moviera a velocidad constante, lo que supuso una mayor exactitud en el funcionamiento del reloj de pesas (Mayr, 2012, p. 21). A pesar de ello, se necesitaba más precisión; lo que consiguió el físico holandés Christiaan Huygens en 1657, al construir un reloj de péndulo aplicando los estudios de Galileo sobre el isocronismo de las oscilaciones del péndulo. En 1660 Robert Hooke realiza varios inventos que incorpora a los relojes portátiles, los que hoy día llamaríamos de bolsillo, aumentando enormemente su precisión. Estos inventos serían el muelle recto, el escape de áncora a retroceso y el escape con dos volantes de compensación (Barquero, 2004, p. 56). Fue precisamente a partir de la segunda mitad del XVII, gracias a estos y otros inventos e innovaciones, cuando se inaugura lo que se ha llamado "la revolución horológica". Produciendo, perfeccionando y abaratando todo tipo de relojes (Mayr, 2012, p. 31). En el siglo XVIII los avances en las máquinas-herramienta hacen posible la construcción de cronómetros de extremada exactitud necesarios para determinar la longitud en los viajes por mar y se fabrican ingenios mecánicos sorprendentes como autómatas y androides.
A finales del siglo XVIII y principios del XIX el auge de los relojes ingleses de bolsillo fue grande en España, lo demuestra el gran número de "ejemplares que quedan hoy, tanto en palacios y museos como en casas particulares" (Herrero, 1955, p. 62). Durante el siglo XIX calendarios y relojes se popularizaron en nuestro país aumentando su demanda, por eso, la centuria del ochocientos ha sido llamada la "edad de oro" (Barquero, 2004, p. 107) de la relojería. A finales del siglo XIX y principios del XX relojes y calendarios eran objetos de uso cotidiano y se encontraban en las aulas, los lugares de trabajo y las viviendas. Los anuncios y la propaganda en la prensa del cambio de siglo demuestran la demanda que tenían este tipo de objetos. Esta demanda espoleó el ingenio de nuestros inventores que se apresuraron a patentar máquinas que regulaban el tiempo o que lo utilizaban como control, explotando la curiosidad y fascinación que provocaban estos aparatos, para comercializar mejor otros artículos o atraer la mirada de posibles clientes.

Hasta aquí decir que he realizado esta sucinta y por supuesto incompleta introducción histórica para mostrar la absoluta integración de los aparatos que miden el tiempo en nuestra cultura y cómo hemos organizado nuestra vida con ayuda de calendarios, relojes y despertadores. Siendo aparatos que consideramos muy necesarios y que demandamos constantemente. A partir de aquí exponer que el objetivo del presente trabajo será analizar cinco patentes históricas realizadas en la Región de Murcia en torno al cambio de siglo. Patentes históricas, relacionadas con el control o la medida del tiempo, que nos servirán para acercarnos a sus inventores, sus logros y la época en que vivieron.

Las fuentes consultadas para el presente artículo serán los documentos originales de dichas patentes que se encuentran en el Archivo Histórico de la Oficina Española de Patentes y Marcas y la prensa local, regional y nacional. Otras fuentes serán los documentos y materiales aportados por las familias Brunton y Anaya entre los que se encuentran el prototipo del cajero, propiedad de la familia Brunton, escrituras públicas de sociedades, marcas y patentes, propiedad de la familia Anaya. Documentos que nos ayudarán a conocer mejor las actividades de estos dos industriales e inventores. Aunque es necesario señalar que los archivos de las familias Brunton y Anaya son archivos privados, no disponibles al público por el momento. Se encuentran todavía sin catalogar y por tanto los documentos carecen de signatura. Agradezco desde aquí a las familias Brunton y Anaya la oportunidad que nos brindan para realizar nuestras investigaciones. 
La investigación que desde hace algunos años estamos realizando sobre historia de la tecnología, Manuela Caballero y el autor del presente trabajo, nos ha permitido iniciar un proyecto cultural titulado "Ingenio y Técnica en la Región de Murcia 18781966". Con dicho proyecto pretendemos investigar, recuperar y divulgar el patrimonio material e inmaterial de la Región de Murcia en el ámbito de la historia cultural de la tecnología. Para ello estamos realizando una exposición itinerante, que lleva el mismo título del proyecto, por diferentes ciudades. La primera de estas exposiciones se llevó a cabo en el segundo trimestre del año 2013 en la Biblioteca Padre Salmerón de Cieza, donde pudimos exponer cinco prototipos originales de inventores murcianos, entre los cuales se encontraba el cajero automático de Brunton y Anaya. Prototipo que cumplía en 2013 justo 100 años. Cajero que se puede apreciar en las figuras 3 y 4 y que se analizará más adelante. Además pudimos disfrutar de documentos originales de patentes, libros, prensa, fotografías y material que las familias amablemente cedieron para la exposición.

Gracias a la difusión realizada por la primera de estas exposiciones, las familias de los inventores están recuperando un rico patrimonio cultural y tecnológico que estamos divulgando en publicaciones e Internet. En la actualidad, el proyecto lo estamos desarrollando como una de las actividades del Centro de Estudios Históricos Fray Pasqual Salmerón, asociación de la que formamos parte, en colaboración con la Biblioteca Padre Salmerón y el IES Diego Tortosa de Cieza.

\section{DOS CALENDARIOS DE FINAL DE SIGLO}

En la Roma antigua el control del tiempo correspondía a sacerdotes y pontífices que fijaban los días de comienzo del mes. El primer día del mes se llamaba "calendas", palabra que viene de "calatio" convocatoria pública que hacía el pontífice de cada ciudad para, después de ofrecer un sacrificio, anunciar las fiestas del mes. También fijaban el día de comienzo de la vendimia y en el que se podía comenzar a beber el vino nuevo. Cada ciudad tenía sus fiestas y divinidades y el calendario se regía por las misteriosas leyes de la religión, que solo los sacerdotes conocían (Coulanges, 2006, p. 197). Podían alargar y acortar los días del año y modificar los días de nombramiento y cese de los cargos públicos, lo que les confería parte del poder político. Todo esto influía directamente en el pago de los tributos del pueblo e introducía motivos de desorden y discordia.
Esta situación de desorden fue solucionada por Julio César al encargar al astrónomo Sosígenes la creación de un calendario que pudiera ser establecido para uso público y por el que se rigiera todo el Imperio. En el año 46 antes de Cristo se implantó el calendario juliano, que era muy similar al egipcio de 12 meses y 365 días, con semanas de 7 días y que solucionaba el cuarto de día, que le sobra al año solar astronómico, añadiendo un día cada 4 años y dando lugar a un año bisiesto de 366 días. Se instituía de esta forma una mejor organización social del tiempo que ayudaba a los poderes civiles y religiosos a controlar mejor las fiestas, el trabajo y el sistema de tributos.

Matemáticos y astrónomos cristianos trabajaron desde el siglo XIII para conseguir un procedimiento matemático de medida del tiempo que se adecuara al dogma cristiano. Lo que se consiguió a partir de la reforma del calendario juliano por el papa Gregorio XIII en 1582. Gracias a las últimas investigaciones (Carabias, 2012), se sabe que dicha reforma fue definitivamente impulsada por dos informes emitidos por una comisión de eruditos de la Universidad de Salamanca. El primero de ellos, en 1515, consiguió ese procedimiento matemático respondiendo a la doble solicitud del papa León X y el rey Fernando el Católico. Procedimiento que fue ratificado por el segundo informe de 1578 que respondía a la segunda solicitud formulada por el papa Gregorio XIII y Felipe II. El nuevo calendario, conocido como gregoriano, ajustaba el retraso producido por el calendario juliano de 11 minutos con el año trópico; que desde el Concilio de Nicea (325) se había acumulado, convirtiéndose en 1582 en una diferencia de 10 días. Además, en el Concilio de Nicea el equinoccio de primavera se fijó el 21 de marzo, pero debido al susodicho retraso, en el Concilio de Trento (1545) el equinoccio coincidió con el 11 de marzo, por lo que la reforma gregoriana anuló 3 años bisiestos y 10 días. Por tanto, al jueves 4 de octubre le siguió el viernes 15 de octubre de 1582 y el equinoccio de primavera volvió a coincidir con el 21 de marzo.

El calendario gregoriano ya no se volvió a modificar y es el que utilizamos en la actualidad como calendario civil del occidente cristiano. Lo hemos asimilado desde el siglo XVI y forma parte integrante de nuestras vidas, de nuestra cultura y de nuestra forma de pensar. De hecho, almanaques y calendarios constituyeron durante siglos una forma de transmisión de cultura económica y popular. Las ediciones de almanaques y calendarios en la Inglaterra del XVII y XVIII tenían tiradas que superaban a la Biblia (Velasco, 2000, p. 121). Eran realmente económicos y se vendían en librerías, 
colmados, mercadillos y eran introducidos por ciegos y buhoneros en todas partes. Eran verdaderos reservorios de la sabiduría y filosofía popular e interesaban a todos ya que abarcaban un amplio número de contenidos e intereses y estaban ilustrados.

En el siglo XIX en España, sobre todo a finales de la centuria tuvo lugar la gran eclosión de la venta de almanaques y calendarios, siendo repartidos muchos de manera gratuita por las empresas e instituciones a sus clientes y usuarios (Velasco, 2000, p. 122). Entre una muestra aleatoria de 55 almanaques y calendarios editados en la España del XIX, tomada entre los años de 1799 y 1902, la mayor parte fueron publicados en la segunda mitad del XIX y más concretamente a partir de 1865, con la aparición de una buena cantidad de magníficas ilustraciones en esas publicaciones periódicas (Botrel, 2003, p. 107). Fue esta por tanto, la de finales del XIX, una época de auge en la venta de estas publicaciones y de gran expectación popular por los avances tecnológicos, ya que la prensa seguía con asiduidad todo tipo de invenciones, entrevistando a los inventores e incluso publicando estas noticias por entregas para mantener la expectación del público.

La primera patente solicitada en España de un calendario fue la número 3853 , solicitada por José Vázquez Rigalt vecino de Barcelona el 4 de enero de 1884 y concedida el 9 de abril del mismo año, con el título de "un nuevo calendario". Fue puesta en práctica con fecha de 22 de febrero de 1886 y caducó al año siguiente por falta de pago. La puesta en práctica debía ser acreditada antes de un tiempo determinado, pues era obligatoria por ley. El Estado se aseguraba por tanto que el invento se explotara industrialmente contribuyendo a la productividad. Si no se hacía, la patente caducaba y pasaba a ser pública por si alguien quería ponerla en práctica (Sáiz, 1999, p. 192). A pesar de que fue puesta en práctica no hemos encontrado noticias de la comercialización de esta patente.

En el siglo XIX encontramos dieciocho patentes que incluyen la palabra calendario en su título. De las cuales solo la primera consta que se puso en práctica. Cinco inventos son patentados por extranjeros y solo dos tienen la segunda anualidad pagada. De las patentes realizadas por españoles, que son trece, cuatro son pagadas durante dos años y en dos solo se llega a pagar hasta la tercera anualidad. De estas dos últimas, una es la primera patente de Vázquez Rigalt. El pago de más de una anualidad puede indicar un cierto esfuerzo por parte de los inventores para mantener el monopolio de la patente. Es posible también, como nos indica Ortiz-Villajos, y por el gran número de patentes que aparecen con una o dos anualidades pagadas, que al inventor solo le interesara mantener el monopolio durante los primeros años de su puesta en marcha, es decir, mientras el invento llegaba a ser rentable. Ya que era poco probable que, aunque caducara la patente, alguien la copiara por el esfuerzo económico que supone hacer rentable un invento y porque la difusión no era tan inmediata como en la actualidad (Ortiz-Villajos, 1999, p. 159).

En 1887 Fulgencio Gil García de Alcaraz, vecino de Cartagena, se decide a patentar sus dos calendarios mecánicos: el primero de accionamiento manual y el segundo automático. Dos inventos presentados con solo algo más de 15 días de diferencia y que por eso tienen una numeración tan parecida. Patentes 7128 y 7178. La primera de ellas "un calendario mecánico", solicitada por Fulgencio Gil en Madrid el 18 de junio de 1887, aparece sin fecha de concesión. Se trata de un calendario (Figura 1) formado por dos rodillos entre los que se enrolla una bobina de papel o tela en la que se encuentran impresos, en su orden conveniente y a una distancia adecuada, todos los días del año con las indicaciones del mes, las fases de la luna, el santoral y todas las que se estimen convenientes. El mecanismo va montado dentro de una caja que tiene dos orificios laterales por donde salen los ejes que terminan en dos pequeñas ruedas moleteadas, para su arrollamiento manual, o en dos pequeñas poleas para que puedan ser movidas por un cordón. La caja se cubre con una tapa que dispone de una ventana frontal cubierta con un cristal, para que no entre polvo y se puedan leer los datos impresos. Los ejes poseen sendos muelles o flejes en los extremos interiores de los ejes que les sirven como freno, necesario para que permanezca tensa la cinta de papel y se aprecien mejor los datos impresos.

Fulgencio Gil debía tener intereses comerciales o bien dedicarse al comercio pues dejó anotado en su patente que la tapa de la caja podría ser "más o menos lujosa y artística según el capricho del público" (Gil, 1887a, p. 2). Máxime cuando encontramos, en la Gaceta Minera de Cartagena y justo un año antes de sus dos patentes, que formó una sociedad "para dedicarse al negocio de comisiones y representaciones comerciales" (Gaceta Minera, 15/06/1886, p 5). La razón social de la sociedad era Conesa y Gil y su socio en esta empresa fue Mariano Conesa. Es posible que Fulgencio Gil y Mariano Conesa tuvieran la idea de inundar el mercado, entre otros artículos, con los fascinantes calendarios patentados por Gil. 

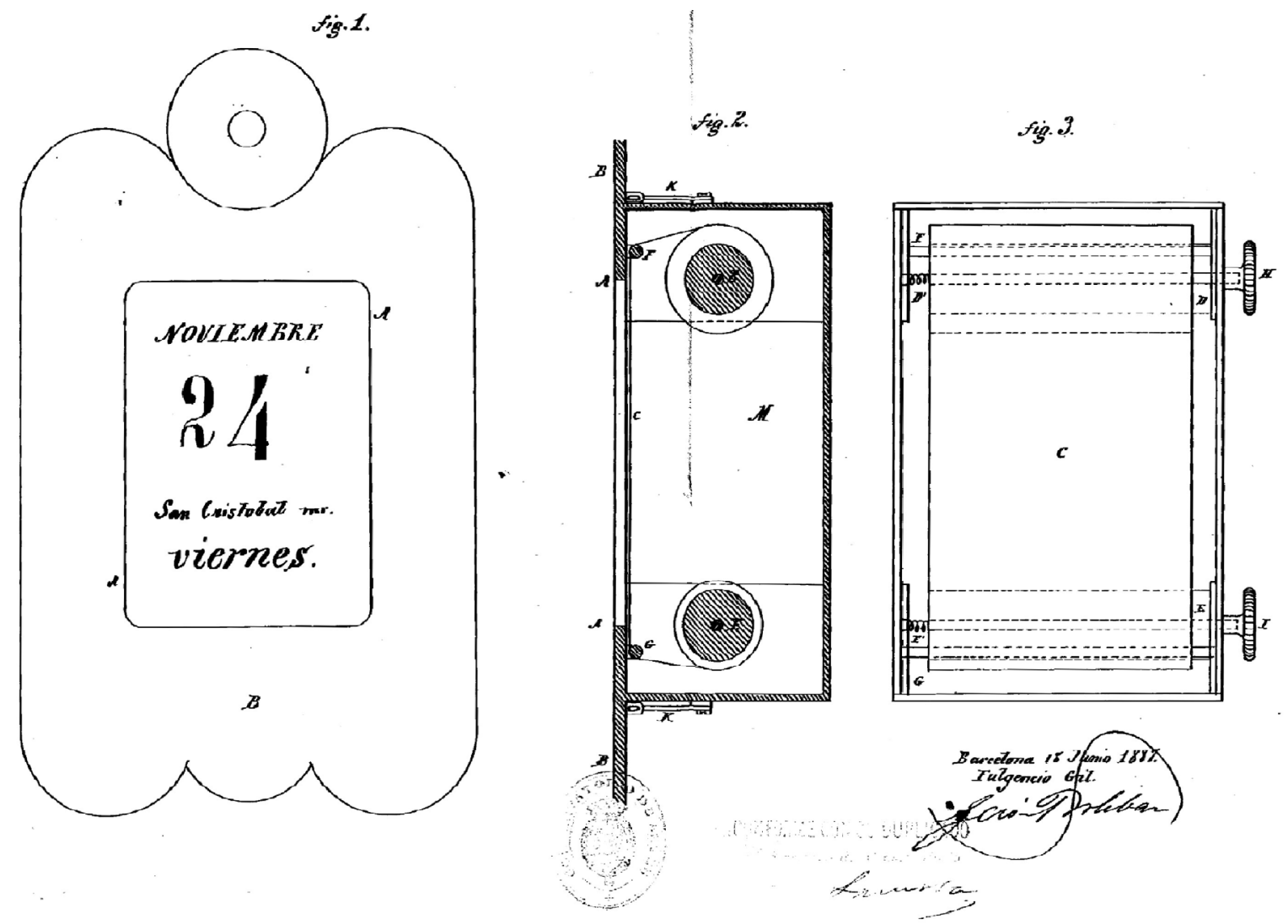

Además, Fulgencio Gil debía llevar bastante tiempo en el mundo del comercio cuando lo encontramos, seis años antes de patentar sus calendarios, como corresponsal principal para Cartagena del Anuario del Comercio, que se anunciaba para suscripción anual en el Eco de Cartagena del 6 de octubre de 1881.

La segunda patente de Fulgencio Gil lleva por título "un calendario automático" y es presentada por su representante, el señor Bolibar, en el Conservatorio de Artes de Barcelona con fecha de 9 de julio de 1887 y concedida el 28 de ese mismo mes. Este segundo calendario era automático gracias a un mecanismo de relojería que movía, cada 24 horas, la cinta de papel necesaria para poder ver los datos impresos del nuevo día. Solo necesitaba que le dieran cuerda como a cualquier reloj. Este segundo calendario, dirigido a un sector del público de mayor poder adquisitivo, constaba de una caja con "tapa elegante y caprichosa" (Gil, $1887 \mathrm{~b}$, p. 1) que se puede apreciar en la figura 2.
No sabemos si Fulgencio Gil fabricó y comercializó sus dos patentes, ya que no hemos encontrado noticias ni publicidad en la prensa de la época, aunque creemos que debió construir los prototipos, pues los diseños, sobre todo de su calendario automático, son realmente precisos y realizados con todo lujo de detalles; incluido todo el funcionamiento y dibujo del mecanismo de relojería. De lo que si estamos seguros es que Fulgencio Gil se debió de tomar muy en serio este proyecto, pues el diseño de sus dos inventos está realmente cuidado y además realizó las gestiones de sus patentes a través de una importante oficina de ingeniería industrial de Barcelona, que se dedicaba a la gestión de patentes y marcas y de la que era director el ingeniero industrial: Gerónimo Bolibar, por aquel entonces, director de la Oficina Internacional de Patentes, establecida en Barcelona y también director de la revista semanal ilustrada: Industria é invenciones, publicación de la misma oficina de pro- 
piedad industrial. En 1885, en un apartado de noticias varias de esta misma revista, se daban instrucciones para que los inventores españoles se animaran a exponer sus ingenios en la Exposición Internacional de Invenciones, que se iba a celebrar en Londres. Bolibar se encargaría, según decía la noticia, de legalizar sus marcas, patentes y modelos en Inglaterra, para que estuviesen protegidas durante la exposición y advirtiendo que el hecho de exponer no perjudicaría el derecho que asistía al inventor para obtener privilegio de invención, siempre que se solicitara la patente dentro de los seis meses siguientes a la inauguración de la exposición (Industria e invenciones, tomo III, no 62, 07/03/1885, p. 347).

\section{Figura 2. Calendario automático de Fulgencio Gil. AHOEPM}

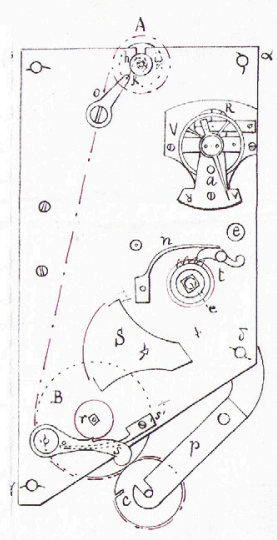

Fis. 1.

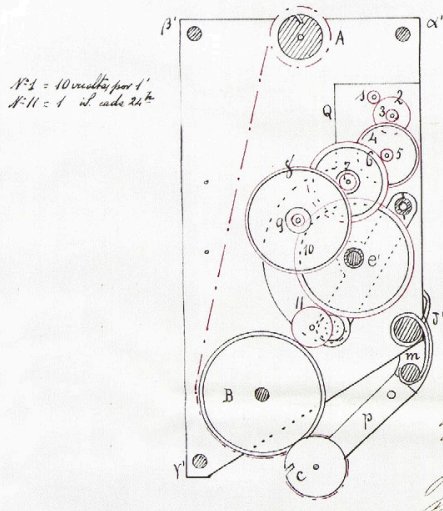

Fie.2.
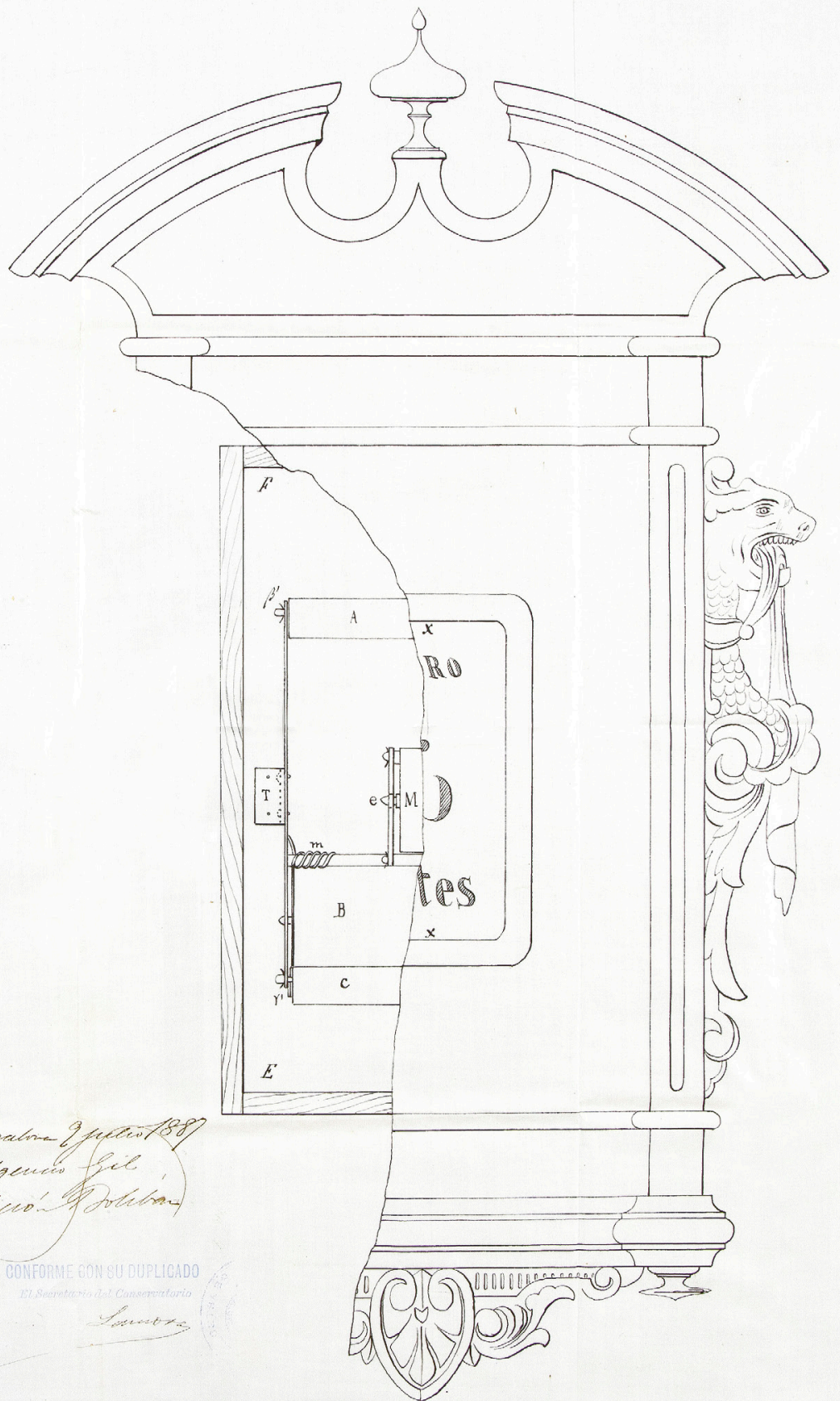

Fis 3 


\section{EL CAJERO AUTOMÁTICO DE BRUNTON Y ANAYA}

Un invento en el que se utilizaría el tiempo para ayudar a controlar la débil voluntad del género humano sería el patentado por Brunton y Anaya en la Cieza de 1913. Se trataba de "Una caja mecánica repartidora de un cierto número de monedas con intervalos de tiempo determinados". De esta manera titularon los dos inventores la patente 55.215 solicitada el 26 de marzo de 1913 y concedida el 15 del mes siguiente. El invento de Brunton y Anaya se podría considerar como precursor de los cajeros automáticos existentes en la actualidad.

Comenzando la segunda década del siglo XX, Cieza, ciudad industrial espartera del sureste español, acogía las empresas, industrias y esfuerzos innovadores de estos dos emprendedores que eran Brunton y Anaya. Bernard Haslip Brunton (1871-1953), más conocido en Cieza como Bernardo H. Brunton, fue un ingeniero inglés que llegó a Cieza en 1896 para montar la primera central hidráulica de producción de electricidad, llamada por su propietario Juan Marín "La Fábrica San Antonio del Menjú" (Montes, 1999, p. 55). Brunton se quedó a dirigir la central hidroeléctrica y se afincó en Cieza, donde se casó y comenzó su actividad industrial como inventor, constructor y mantenedor de maquinaria, llegando a patentar, además del cajero, seis inventos relacionados con el majado y las hilaturas del esparto.

Luis Anaya Amorós (1865-1951), comerciante y empresario minero en Cieza, concibió desde joven la idea de hilar y tejer de forma mecánica el esparto para obtener tejidos suaves, tupidos y económicos. Para ello se necesitaba realizar una serie de tratamientos físicoquímicos y procedimientos mecánicos que aportaran la suavidad necesaria a la hilaza de esparto. Anaya llegó a patentar, además del cajero, cuatro patentes relacionadas con el tratamiento de la hilaza del esparto y la confección de sacos.

Brunton por su parte creó también el "Garage Inglés" (Nueva Cieza, 24/08/1922, p. 5) que se dedicaba a la construcción y mantenimiento de todo tipo de maquinaria y calderería y también a la venta y reparación de vehículos. Anaya, por su cuenta, creó una fábrica de hilados y tejidos de esparto que llevaría su nombre y que se dedicaba a la fabricación de todo tipo de tejidos de esparto, filtros para el prensado de aceite y confección de sacos para abonos y transporte de minerales.

Fue precisamente en ese año de 1913, tan prolijo para estos dos inventores, cuando se deciden a pa- tentar su idea concebida para ayudar al ahorro familiar utilizando el tiempo como elemento de control. El ingenio titulado "Una caja mecánica repartidora de un cierto número de monedas con intervalos de tiempo determinados" es descrito en su patente como una caja de caudales. En su interior contiene una serie de tubos verticales (figura 4) de diferentes diámetros donde se alojan las monedas que la familia dedicaría al gasto diario del hogar. Debajo de los tubos se encuentra una placa deslizante en la que se han realizado unos orificios circulares, de suficiente diámetro y espesor para que se aloje la primera de las monedas que se encuentran apiladas en cada tubo. La caja posee un reloj donde se puede preseleccionar un intervalo de tiempo determinado, a modo de despertador, que cuando alcanza la hora programada, y de forma automática, libera un pestillo o cerrojo que permite abrir la placa deslizante y sacar las monedas. Una vez introducida de nuevo dicha placa caen por su peso las monedas, encajándose cada una en su orificio. Al mismo tiempo se arma de nuevo el cerrojo comenzando un nuevo ciclo.

El documento de la patente está formado por una memoria mecanografiada que no tiene planos ni esquemas, quedando a la imaginación del lector cómo sería el cajero. Gracias a la familia Brunton se ha podido recuperar uno de los prototipos fabricados por los inventores, que se puede apreciar en las figuras 3 y 4 . La patente figura como puesta en práctica con fecha de 15 de junio de 1916 y de hecho sus inventores crearon una sociedad mercantil regular colectiva, por 10 años contando a partir del 1 de julio de 1913, cuya razón social fue "Brunton y Anaya" con domicilio en la ciudad de Cieza y escritura otorgada el 2 de julio de 1913 por el notario de Barcelona Guillermo A. Tell Lafont. (Sociedad inscrita en el Registro Mercantil de Murcia en la hoja № 759, folio 129 del cuaderno provisional, tomo 26 de Sociedades, inscripción 1a Murcia a 27 de agosto de 1913). Siendo el objeto de dicha sociedad la explotación de patentes industriales y demás objetos de industria y cualesquiera otra clase de operaciones de lícito comercio que acordaran los socios. El capital social de la empresa fue de 3.000 pesetas aportado a la caja social por mitad, en la siguiente forma: Brunton aportaba las patentes siguientes y por este orden:

- Patente de Invención no 47.437. Un nuevo producto industrial, consistente en un tejido formado por la combinación de esparto hilado con otras fibras como cáñamo, yute, abacá o cualquier otra que se preste a la filatura. Concedida el 07-03-1910 y puesta en práctica el 16-05-1913. Fecha en la escritura de 21 de mayo de 1910. 
- Patente de Invención no 48.213. Mejoras en el procedimiento del hilado mecánico de fibra de esparto. Concedida el 09-07-1910 y puesta en práctica el 21-08-1912. Fecha en la escritura de 6 de agosto de 1910.

- Patente de Invención no 47.438. Un nuevo producto industrial, consistente en esparto hilado mecánicamente con arreglo al procedimiento que se describe. Concedida el 07-03-1910 y puesta en práctica el 19-05-1913. Fecha en la escritura de 21 de mayo de 1910.

- Patente de Invención no 54.110. Una máquina para majar esparto u otras materias textiles. Concedida el 08-11-1912 y puesta en práctica el 03-01-1916. Fecha en la escritura de 15 de noviembre de 1912.

- Y la mitad de la patente de Invención no 55.215. Una caja repartidora de un cierto número de monedas con intervalos de tiempo determinados. Concedida el 15-04-1913 y puesta en práctica el 15-06-1916. Fecha en la escritura de 15 de abril de 1913. Expedidas todas por la Dirección General de Agricultura, Industria y Comercio de España y valoradas por los socios en 1.500 pesetas.
Anaya aportaba al capital social de la empresa la mitad de la patente 55.215 y 1.000 pesetas en efectivo.

Además, se entenderían aportadas a la sociedad las patentes que se registraran en lo sucesivo en otras naciones sobre el objeto de las que constaban las ya aportadas. La gerencia, administración y uso de la firma social correspondería de forma indistinta a ambos socios.

Brunton y Anaya decidieron también registrar la marca de fábrica para su invento al que llamaron "Autocajero". Marca que fue expedida por el Director General de Comercio, Industria y Trabajo en Madrid a 17 de febrero de 1914 e inscrita en el Registro de la Propiedad Industrial, libro 6, folio 146, № 23.085.

Como se puede apreciar, no fueron pocos los esfuerzos que estos dos emprendedores dedicaron a su cajero automático y tampoco era cuestión baladí el objetivo que se propusieron con su invento. El cual se puede leer en su patente: "facilitar a las familias que quieran o necesiten dar una buena administración a sus bienes, el medio de repartir a su comodidad y con rigurosa exactitud la cantidad que destinen al gasto diario" (Brunton, Anaya, 1913, p. 1).

\section{Figura 3. Cajero de Brunton y Anaya. Foto del autor}

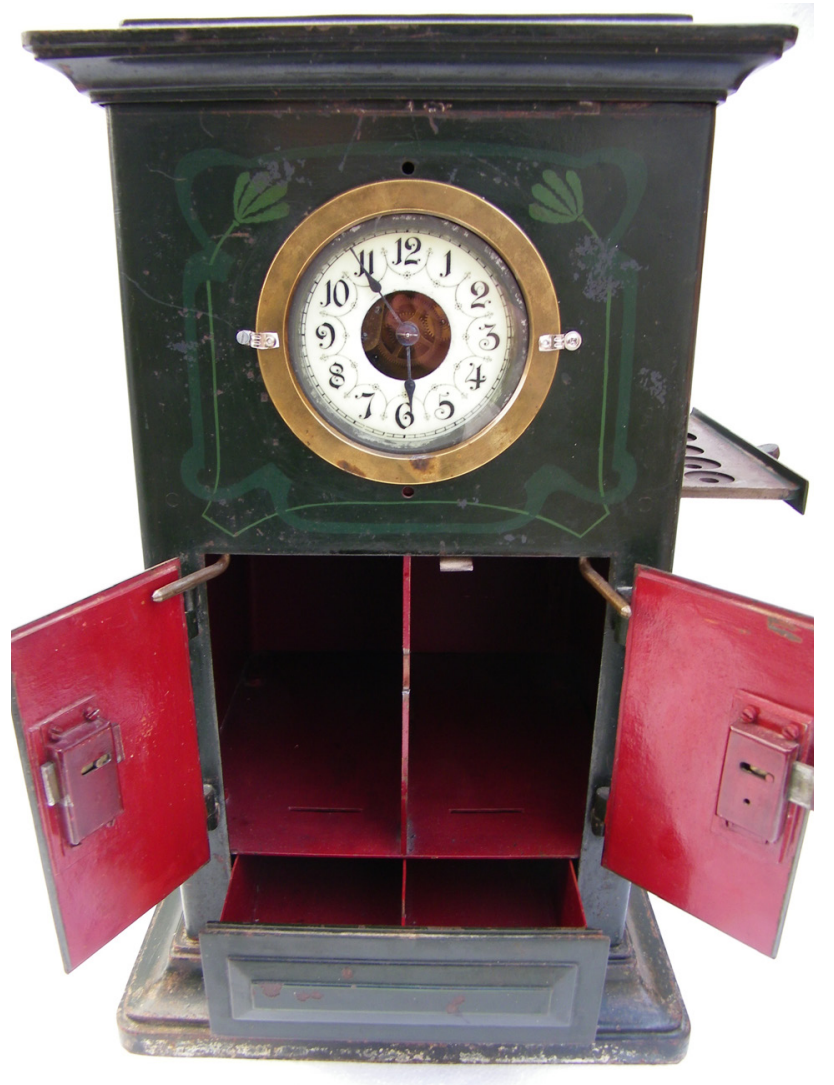


Figura 4. Cajero de Brunton y Anaya. Foto del autor

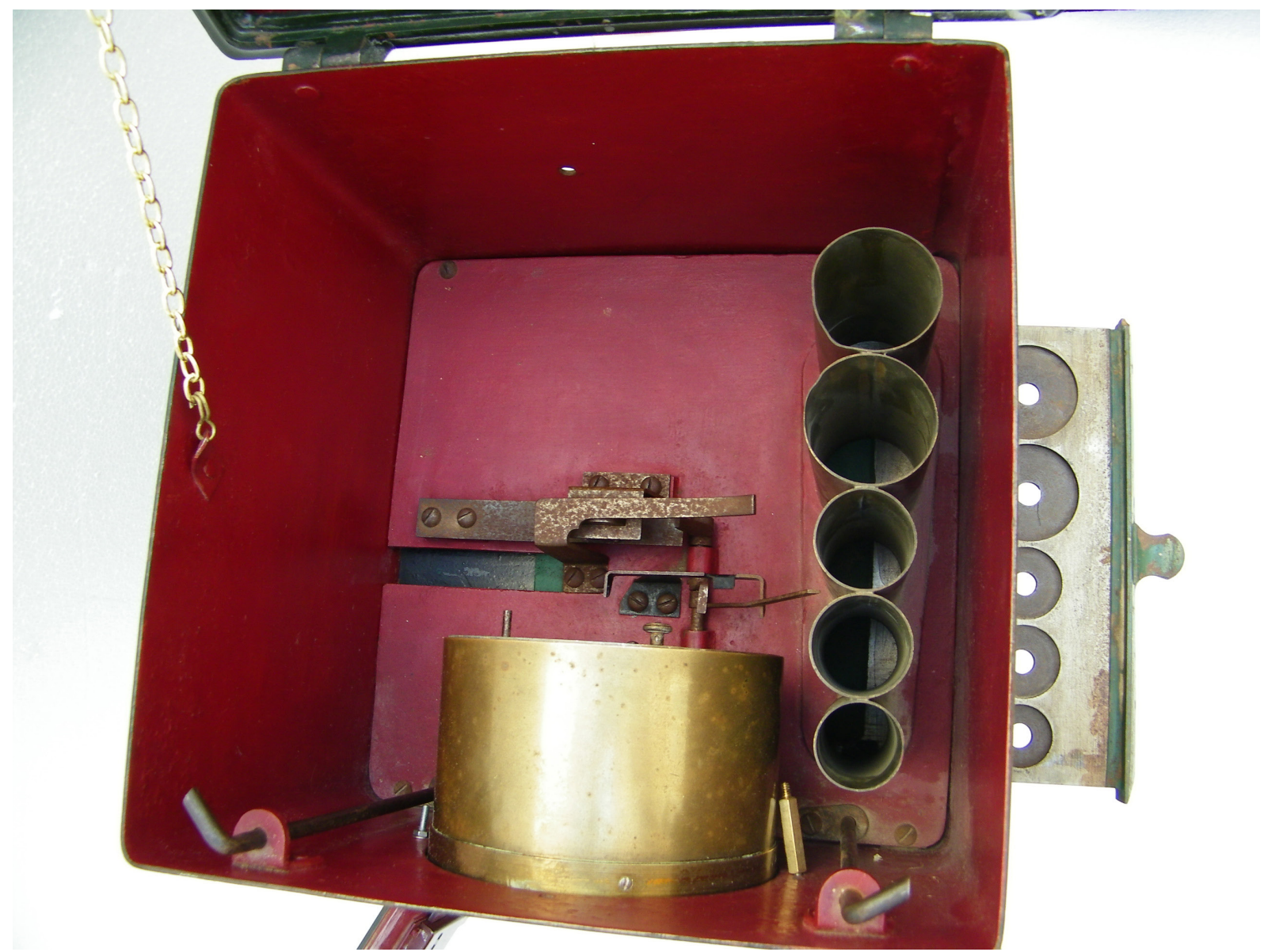

Para finalizar, los inventores justificaban su patente exponiendo que los gastos familiares, el lujo y los atractivos de la vida superan al sueldo que se percibe y resulta muy difícil no malgastar los limitados recursos de que se dispone. Con su "Autocajero" facilitarían la ayuda necesaria a la débil voluntad humana utilizando el tiempo para obligar al reparto diario del dinero estipulado, que evitaría la ruina de la familia y educaría "a las generaciones futuras enseñándoles el camino del ahorro, principal elemento de las familias y de los pueblos que quieren llegar a ser grandes" (Brunton y Anaya, 1913, pp. 2-3).

\section{UN RELOJ EXPENDEDOR DE CERVEZA}

El conocido maestro hojalatero de la ciudad de Murcia, Manuel Pérez Nicolás, solicitó patente de invención por 20 años el 15 de mayo de 1928. El título era: "Un aparato para la venta de cerveza y otros líquidos, consistente en una caja de reloj despertador". Este invento solucionaba el problema que los establecimientos pú- blicos que servían cerveza en 1928 tenían, ya que no podían mantener en todo momento la cerveza helada que exigía la demanda. El aparato consistía en una caja de metal, que según el inventor, podía construirse con cualquier metal y cualquier forma, pero que él había diseñado con una forma muy curiosa de reloj-despertador para atraer la atención del público. Diseño que puede apreciarse en las figuras 5 y 6 . La reivindicación del inventor era que dentro de esa caja de metal se encontraba el depósito de los líquidos en contacto directo con el hielo. Cuando habla de líquidos se refiere a la cerveza o cualquier otro que pudiera consumir el público. Además, sabemos que al menos construyó un prototipo pues así lo expresa en su patente.

Dicho esto, lo que más nos llama la atención es el curioso diseño con que Pérez Nicolás realizó su invento y nos sorprende que la prensa no hablara de este invento, pues hemos encontrado numerosas noticias que siguen el trabajo de este maestro hojalatero de Murcia. Incluso una de otro invento que realizó 36 años antes y 
que también patentó: un aparato titulado "inodoro automático para sumideros y alcantarillas". Patente 13.084 que le fue concedida el 5 de mayo de 1892. Invento que puso a disposición del Ayuntamiento de Murcia por su utilidad pública y que tuvo eco en varios periódicos de Murcia, llegando los redactores a pedir que le permitieran ensayarlo: "El joven y conocido maestro hojalatero Manuel Pérez ha ofrecido al ayuntamiento el aparato de su invención "Inodoro automático», para sustituir con él las actuales regillas del alcantarillado. Dicho aparato, por el cual se le ha concedido al autor real privilegio de invención, hace las veces de la regilla, absorbe una cantidad de agua mayor, y tiene la propiedad de que, una vez terminado su funcionamiento, queda herméticamente cerrado é impide la salida á las emanaciones pestilentes y molestas de las alcantarillas. Creemos que el aparato del Sr. Pérez merece ensayarse." (Diario de Murcia, 28/07/1892, p. 3).
Manuel Pérez Nicolás debía ser un empresario emprendedor e ingenioso pues se elogiaban mucho sus trabajos en la prensa de la época, como el caso de la crestería que realizó en 1894 para coronar la fachada del Teatro Romea de Murcia: "Se ha terminado la colocación de la bonita crestería de la fachada del Teatro Romea, construida por el inteligente y aventajado maestro hojalatero don Manuel Pérez. Dicho trabajo está muy bien hecho y ha sido todo construido en el taller del Sr. Pérez, quien cada día introduce en su establecimiento nuevos aparatos para poder realizar en esta capital trabajos como el que nos ocupa, que otras veces ha habido que encomendar fuera, por necesidad. Reciba el Sr. Pérez nuestro entusiasta aplauso por su obra y recíbalo también el Sr. Alcalde que la ha encomendado á un trabajador del país." (Las Provincias de Levante (Murcia), 19/11/1894, p. 3).

\section{Fig. 5. Expendedor de cerveza con forma de reloj. AHOEPM}
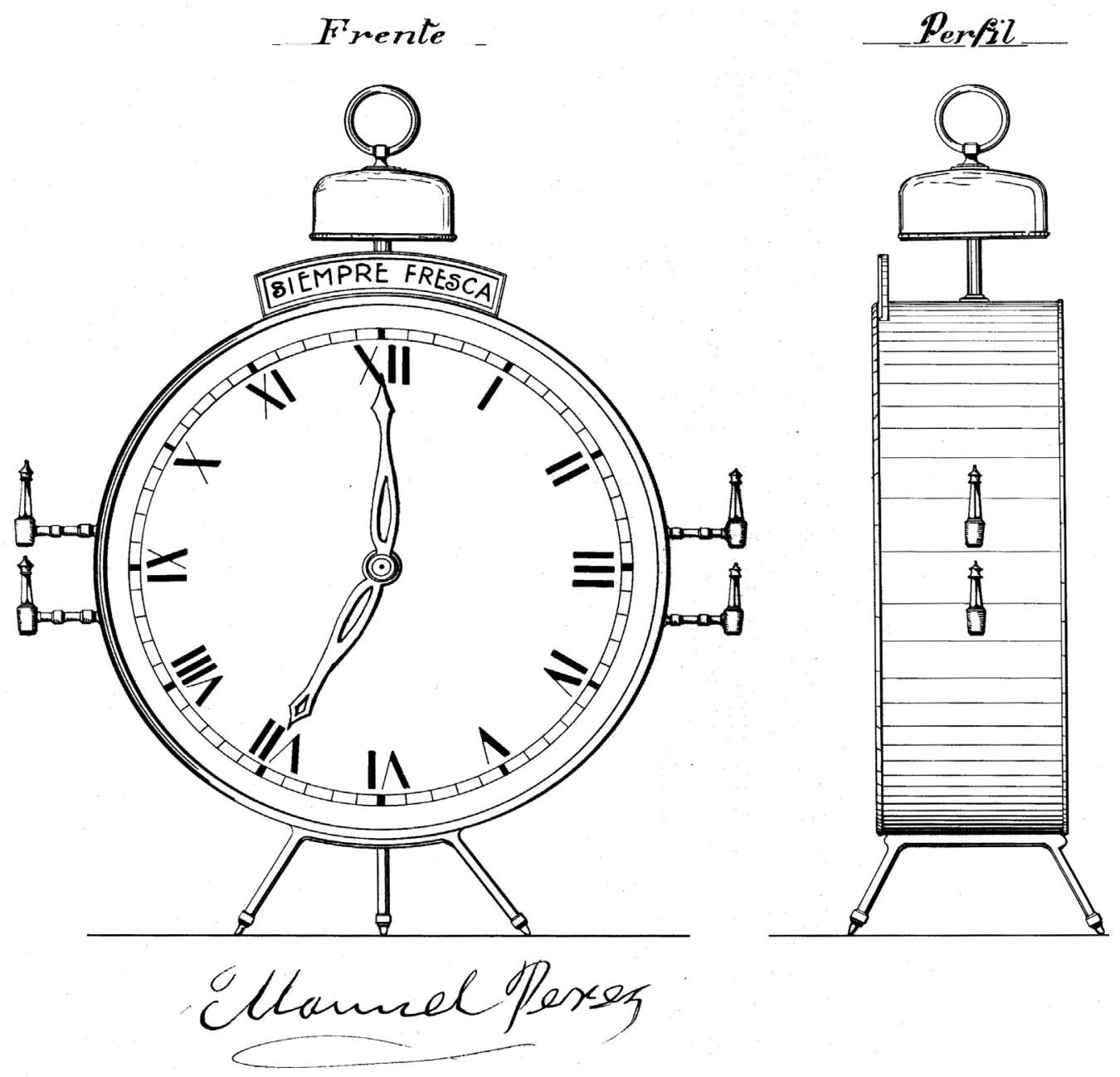


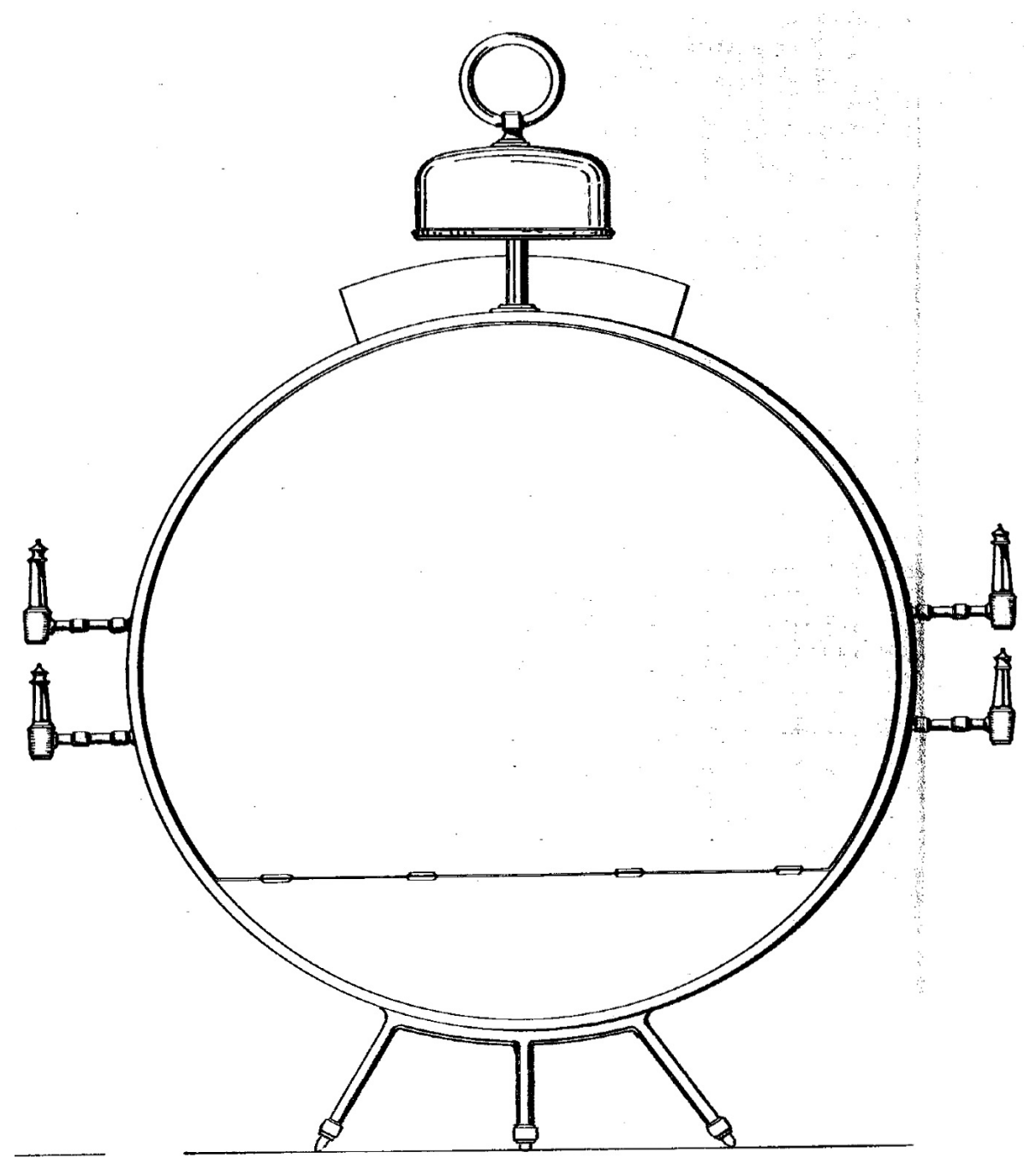

No era raro, por tanto, que Manuel Pérez, hombre acostumbrado a sorprender con sus diseños, buscara atraer la atención del público con su nuevo aparato expendedor de cerveza helada, diseñado con una forma tan innovadora para un expendedor de cerveza, y a la vez tan cotidiana para todos como un reloj despertador. El diseño de Manuel Pérez, relacionado con los aparatos para controlar el tiempo, nos habla de dos ideas claves para el marketing y la publicidad actual: El sorprender constantemente al público, que Manuel Pérez consigue doblemente por la expectación que levantaban los relojes en la época del cambio de siglo y por utilizar una técnica para sorprender con el diseño de la envoltura, con la forma del envase del producto que se vende, que en este caso es la cerveza, y que en la actualidad se llama "packaging" (Serrano y Biel, 2012), muy utilizada hoy día, resultando una poderosa herramienta para aumentar las ventas. La segunda idea tiene que ver con la cotidianeidad del diseño que lo acerca más al cliente que es el receptor del mensaje publicitario. El reloj despertador que es, ya desde el siglo XIX, "el aparato más cercano al ser humano mientras duerme" (Cabrera, 2006, p. 96) y que junto al reloj de pulsera, popularizado después de la Primera Guerra Mundial, forman parte de nuestra cultura cotidiana y están íntimamente insertados en nuestras 
vidas. Como ha escrito Eloísa Nos: "El discurso publicitario se caracteriza por sorprender constantemente, pero al mismo tiempo, por tratar de ser natural, por acercarse al máximo a las maneras de hablar de la gente, a su cotidianeidad (debido a su carácter de comunicación masiva, por un lado, y a su búsqueda de cercanía con el receptor, por otro)" (Nos, 2007, p. 55).

Quizás Manuel Pérez hubiera ganado un premio si hubiera presentado su invento a un concurso de diseño o se hubiera divulgado más ampliamente su aparato, como ocurrió con la cafetera Chemex, diseñada por el químico alemán Peter Schlumbohm en 1940 que creó una cafetera de vidrio pirex con forma de reloj de arena y que en el centro, donde se aloja el filtro, colocó un collar de madera pulida con una corbata de piel que se utilizaba para servir el café. Esta cafetera fue seleccionada por el Instituto de Tecnología de Illinois como uno de los 100 mejores diseños de los últimos tiempos. Otro invento utilizado para servir líquidos alimentarios y que se diseñó con una forma similar a la de un aparato para medir el tiempo, el reloj de arena.

\section{UN RELOJ LUMINOSO ANUNCIADOR}

La última patente analizada en este trabajo también tiene que ver con la utilización de un reloj para atraer la atención del público. En este caso se trata de la solicitada por Manuel Ruiz Ruiz, vecino de Cartagena, el 7 de septiembre de 1928 y concedida diez días después, titulada: Un aparato anunciador con reloj luminoso de servicio público". Dicha patente consistía en un aparato anunciador formado por una caja de madera, cuyas dimensiones y detalles se pueden apreciar en la figura 7 , con 5 cajones que llevan una luna de cristal en su frente, donde se pueden pintar anuncios, dibujos y alegorías. Estas lunas de cristal podían ser cambiadas gracias a una portezuela que llevaba en su lado derecho y a unas guías con una ranura por donde se podían sacar y meter los cristales. Detrás de cada luna llevaba dos lámparas eléctricas que permitían se vieran los anuncios durante la noche.

El aparato anunciador llevaba un reloj en lo alto con una esfera iluminada donde también se podía poner un anuncio pequeño, siendo este reloj de fabricación especial para este tipo de anuncios. El funcionamiento del reloj estaba garantizado y tenía una autonomía de cuerda para ocho días como mínimo. Según Ruiz, estos aparatos anunciadores, estaban concebidos para ser colocados en las fachadas de los establecimientos y se pudieran visualizar de día y de noche.
Gracias a la prensa de la época sabemos que en 1927 se crea la ambiciosa: Agencia de publicidad RA$F A E L$, dirigida por el conocido periodista Rafael Faustino, que pretendía acaparar el mercado de la propaganda en Cartagena y extender sus límites fuera de la Región de Murcia. La noticia se expresaba en estos términos: "Agencia de publicidad «RAFAEL» En breve será inaugurada esta Agencia, primera que habrá en Cartagena, dirigida por nuestro buen amigo, el ya popular periodista D. Rafael Faustino. La propaganda comercial e industrial, en Cartagena, estaba casi virgen, falta de que un espíritu emprendedor y conocedor del asunto la atacara de frente; y si a esto se añade que dicha Agencia extenderá su acción más allá de los límites de la provincia, de presumir es que la empresa cristalice en realidades que han de beneficiar, no solo a aquélla, sino al Comercio, a la Industria y a Cartagena. ¡Que así suceda, es lo que de veras deseamos en esta Casa!" (Cartagena Ilustrada, 31/10/1927, p. 15).

Es en esta empresa donde encontramos trabajando a Manuel Ruiz en otra noticia de 1928: "El Ayuntamiento de Cartagena autoriza [...] a don Manuel Ruiz Ruiz para la colocación de anuncios de la Agencia de Publicidad "Rafael»" (Cartagena Nueva, 05/08/1928, p. 1). Probablemente, el inventor debía ser técnico electricista, ya que era el encargado de la colocación e instalación de los anuncios luminosos, como podemos leer en la siguiente noticia: "Requerir a don Manuel Ruiz para que presente croquis y aclaraciones sobre proyecto de anuncio luminoso en la plaza de Valarino Togores." (La Tierra, 14/08/1928, p. 3).

Se puede pensar que incluso podía ser socio fundador y trabajador de la referida agencia de publicidad, por el celo, la realización de la patente que nos ocupa y la frecuencia con que es nombrado en la prensa cartagenera, justo en el mismo año en que realiza su invento. Además, en la memoria de su patente, deja claro que los aparatos anunciadores de su invención se instalarían en toda España, coincidiendo con la política expansionista de la Agencia de publicidad «RAFAEL». De hecho, Manuel Ruiz da todas las señas de ser un profesional avezado en la publicidad, cuando advierte en su patente que: "El referido aparato representa una novedad muy sugestiva en el ramo de la Publicidad pues no solo la luminosidad que irradia, sino la indicación de la hora fija que facilita al público, hará recaer sobre él, las miradas de los transeuntes" (Ruiz, 1928, p. 2). Un segundo invento en la Región de Murcia en el que se explotan, de forma inteligente, la expectación, la curiosidad y la necesidad de organizar nuestra jornada, gracias a los relojes, que hemos interiorizado a lo largo de los siglos. 


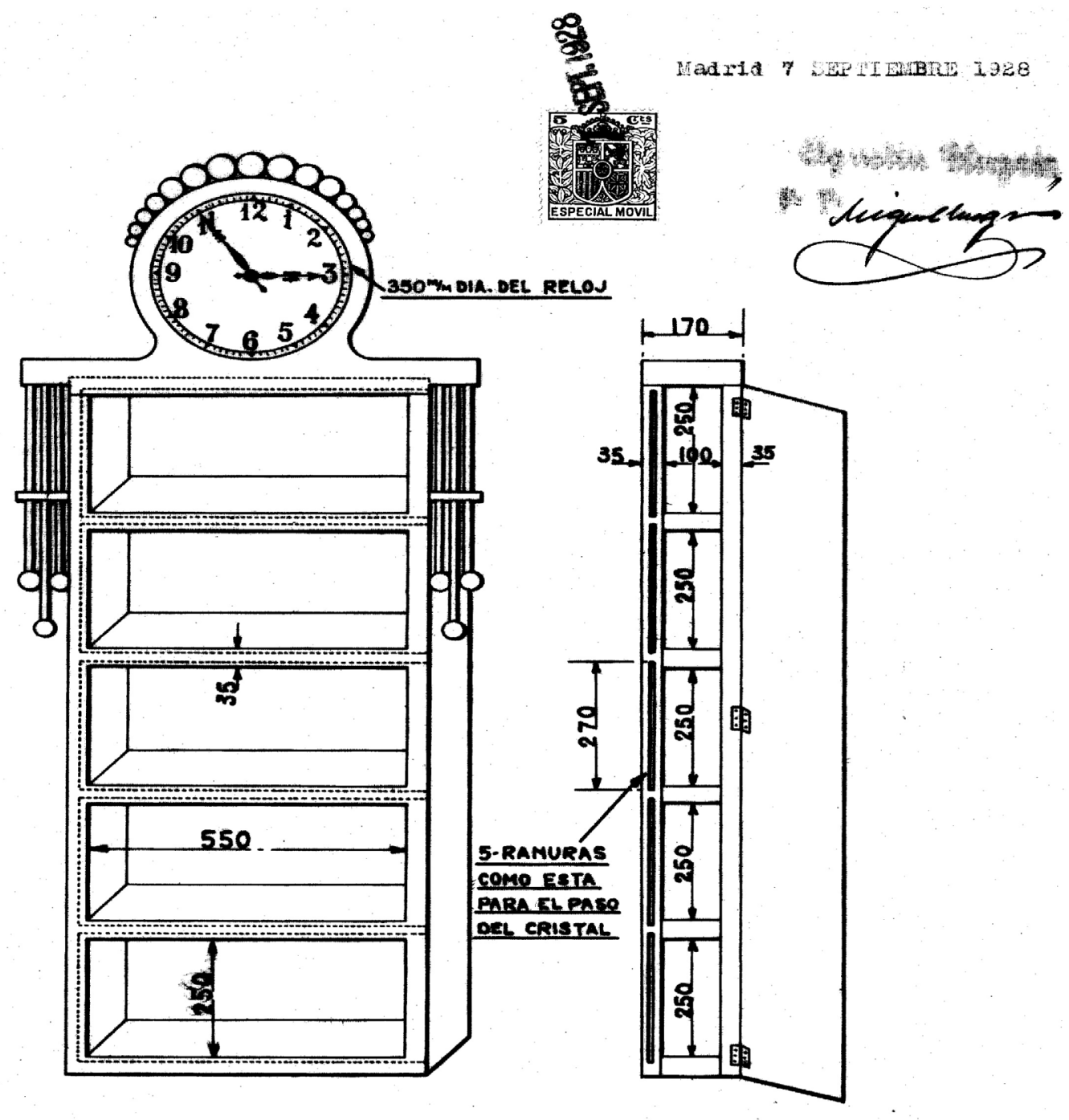

\section{CONCLUSIONES}

No cabe duda de que el dominio del tiempo ha sido explotado por las élites de la humanidad para regir y controlar las sociedades, afianzando su poder y prestigio social y sucediéndose a lo largo de la historia infinidad de hitos relacionados con este tema: cambios en el inicio de los días del mes, instauración y reforma de calendarios, invención y desarrollo de aparatos para medir el tiempo y máquinas que realizarían acciones automáticas gracias a un mecanismo de relojería. Con el paso de los siglos estas nuevas invenciones fueron no solo aceptadas, sino también demandadas, llegando a formar parte de nuestra vida cotidiana.
A finales del siglo XIX y principios del XX relojes y calendarios eran objetos de uso cotidiano. Los anuncios y la propaganda en la prensa demuestran la demanda que tenían este tipo de objetos. Fue una época de auge en la venta de almanaques y calendarios y también de gran expectación popular por los avances tecnológicos. Es precisamente durante este clima favorable cuando se patentan cinco inventos en la Región de Murcia cuya temática, relacionada con el control del tiempo, ha resultado ser una buena motivación para que fueran analizados juntos en el presente artículo.

La noticia encontrada en 1886 de que Fulgencio Gil García de Alcaraz creó la sociedad Conesa y Gil para 
dedicarse al negocio de representaciones comerciales y sus dos calendarios, patentados justo meses después, nos demuestra que efectivamente existía ese clima favorable de venta, desarrollo y modernización de estos aparatos, pues el primero que patenta es mecánico de accionamiento manual y aparece sin fecha de concesión ya que no se le dio curso. Pero solo quince días después Gil patenta un calendario también mecánico pero más elaborado y de accionamiento automático. Quizás porque era lo que demandaba el público o porque ya existieran calendarios parecidos al primero, que estuvieran acaparando el mercado. No lo sabemos a ciencia cierta. Lo que si parece probable es que la creación de su sociedad motivara a Gil para patentar sus calendarios y poder así venderlos a través de su empresa.

Por otra parte, en el caso del cajero automático de Brunton y Anaya queda demostrado, gracias a la documentación aportada por los familiares, que pensaban comercializarlo a gran escala, pues ese mismo año de 1913 crean la sociedad mercantil regular colectiva "Brunton y Anaya". Además, dicha sociedad fabricó varios de estos cajeros automáticos y registró, en 1914, la palabra "Autocajero" como marca de fábrica para su patente. Cajero que fue creado para ayudar a controlar la débil voluntad del género humano utilizando el tiempo como elemento de control y que podría considerarse como precursor de los cajeros automáticos existentes en la actualidad.

Los dos inventos patentados en 1928 en la Región de Murcia son diseños utilizados para favorecer el marketing y la publicidad respectivamente. Por un lado, el aparato expendedor de cerveza helada fue diseñado con la forma de un reloj despertador con el objetivo de atraer la atención del público y poder aumentar la venta de cerveza. Diseño de Manuel Pérez que resulta muy innovador para el momento en que lo patenta, pues utiliza una potente técnica de marketing llamada "packaging", aunque él no la conociera como tal. En el segundo caso se trata del aparato anunciador formado por cinco carteles luminosos y un reloj en su parte superior, con el objetivo de ser utilizado en la publicidad de los anuncios expuestos gracias a la iluminación de cada cartel y al reloj que atraería las miradas por la necesidad que tenemos de organizar nuestra vida midiendo el tiempo. Necesidad poderosa que forma parte de nuestra memoria colectiva y de nuestra cultura.

\section{FUENTES DOCUMENTALES}

\section{Prensa:}

Eco de Cartagena, 06/10/1881.

Industria e invenciones, tomo III, no 62, 07/03/1885.

Gaceta Minera, 15/06/1886.

Diario de Murcia, 28/07/1892.

Las Provincias de Levante (Murcia), 19/11/1894.

Nueva Cieza, 24/08/1922.

Cartagena llustrada, 31/10/1927.

Cartagena Nueva, 05/08/1928.

La Tierra, 14/08/1928.
Escritura de la Sociedad Brunton y Anaya inscrita en el Registro Mercantil de Murcia en la hoja № 759, folio 129 del cuaderno provisional, tomo 26 de Sociedades, inscripción 1a Murcia a 27 de agosto de 1913.

Brunton, B. H. y Anaya Amorós, L. (1913). Una caja mecánica repartidora de un cierto número de monedas con intervalos de tiempo determinados. Patente no 55215. Cieza: AHOEPM.

Gil García, F. (1887a). Un calendario mecánico. Patente no 7128. Cartagena: AHOEPM.
Gil García, F. (1887b). Un calendario automático. Patente no 7178. Cartagena: AHOEPM.

Pérez Nicolás, M. (1928). Un aparato para la venta de cerveza y otros líquidos, consistente en una caja de reloj despertador Patente $n$ o 107714. Murcia: AHOEPM.

Ruiz Ruiz, M. (1928). Un aparato anunciador con reloj luminoso de servicio público. $\mathrm{Pa}$ tente $\mathrm{n}$ ㅇ 109214. Cartagena: AHOEPM. 


\section{BIBLIOGRAFÍA}

Barquero, J. D. (2004). Enciclopedia del reloj de bolsillo: Historia, catalogación, mecánica y detalles de las mayores colecciones públicas, privadas y museos internacionales. Barcelona: Amat Editorial.

Botrel, J.-F. (2003). Almanachs et calendriers en Espagne au XIXe siècle: essai de typologie. En: Lüsebrink, H.-J. Les lectures du peuple en Europe et dans les Amériques du XVII au XX siècle. BruxeIles: Editions Complexe, pp. 105-126.

Cabrera, D. H. (2006). Lo tecnológico y lo imaginario: las nuevas tecnologías como creencias y esperanzas colectivas. Buenos Aires: Biblos.

Carabias Torres, A. M. (2012). Salamanca y la medida del tiempo. Salamanca: Universidad de Salamanca.

Coulanges, F. (2006). La Ciudad Antigua. Valladolid: Maxtor.
Herrero García, M. (1955). El reloj en la vida española. Madrid: Roberto Carbonell Blasco.

Mayr, O. (2012). Autoridad, libertad y maquinaria automática en la primera modernidad. Barcelona: Acantilado.

Montes Bernárdez, R. (1999). La energía que ilumina. Historia de la iluminación en la Región de Murcia (1797-1935). Murcia: Consejería de Industria, Trabajo y Turismo, CajaMurcia.

Nos Aldás, E. (2007). Lenguaje publicitario y discursos solidarios: eficacia publicitaria, ¿eficacia cultural? Barcelona: Icaria Editorial.

Ortiz-Villajos, J. M. (1999). Tecnología y desarrollo económico en la historia contemporánea: estudio de las patentes registradas en España entre 1882 y 1935. Madrid: Oficina Española de Patentes y Marcas.
Sáiz González, J. P. (1999). Invención, patentes e innovación en la España contemporánea. Madrid: Oficina Española de Patentes y Marcas.

Serrano Tierz, A. y Biel Ibáñez, M. P. (2012). Estética del producto industrial y su representación gráfica. Zaragoza: Universidad de Zaragoza.

Velasco, H. M. (2000). Cultura tradicional en fragmentos. Los almanaques y calendarios y la cultura 'popularizada'. En: Díaz Viana, L. y Godino López, A. (eds.), Palabras para el pueblo (vol. I: Aproximación general a la literatura de cordel). Madrid: Consejo Superior de Investigaciones Científicas, pp. 121-144. 